\title{
Aerosol contribution to the rapid warming of near-term climate under RCP 2.6
}

Article

Published Version

Chalmers, N., Highwood, E. J., Hawkins, E., Sutton, R. T. and Wilcox, L. J. (2012) Aerosol contribution to the rapid warming of near-term climate under RCP 2.6. Geophysical Research Letters, 39 (18). L18709. ISSN 0094-8276 doi: https://doi.org/10.1029/2012GL052848 Available at https://centaur.reading.ac.uk/29182/

It is advisable to refer to the publisher's version if you intend to cite from the work. See Guidance on citing.

To link to this article DOI: http://dx.doi.org/10.1029/2012GL052848

Publisher: American Geophysical Union

All outputs in CentAUR are protected by Intellectual Property Rights law, including copyright law. Copyright and IPR is retained by the creators or other copyright holders. Terms and conditions for use of this material are defined in the End User Agreement.

\section{www.reading.ac.uk/centaur}

\section{CentAUR}

Central Archive at the University of Reading 
Reading's research outputs online 


\title{
Aerosol contribution to the rapid warming of near-term climate under RCP 2.6
}

\author{
N. Chalmers, ${ }^{1,2}$ E. J. Highwood, ${ }^{1}$ E. Hawkins, ${ }^{1,2}$ R. Sutton, ${ }^{1,2}$ and L. J. Wilcox ${ }^{1}$ \\ Received 2 July 2012; revised 16 August 2012; accepted 19 August 2012; published 27 September 2012.
}

[1] The importance of aerosol emissions for near term climate projections is investigated by analysing simulations with the HadGEM2-ES model under two different emissions scenarios: RCP2.6 and RCP4.5. It is shown that the near term warming projected under RCP2.6 is greater than under RCP4.5, even though the greenhouse gas forcing is lower. Rapid and substantial reductions in sulphate aerosol emissions due to a reduction of coal burning in RCP2.6 lead to a reduction in the negative shortwave forcing due to aerosol direct and indirect effects. Indirect effects play an important role over the northern hemisphere oceans, especially the subtropical northeastern Pacific where an anomaly of $5-10 \mathrm{Wm}^{-2}$ develops. The pattern of surface temperature change is consistent with the expected response to this surface radiation anomaly, whilst also exhibiting features that reflect redistribution of energy, and feedbacks, within the climate system. These results demonstrate the importance of aerosol emissions as a key source of uncertainty in near term projections of global and regional climate. Citation: Chalmers, N., E. J. Highwood, E. Hawkins, R. Sutton, and L. J. Wilcox (2012), Aerosol contribution to the rapid warming of near-term climate under RCP 2.6, Geophys. Res. Lett., 39 L18709, doi:10.1029/ 2012 GL052848.

\section{Introduction}

[2] The forthcoming Fifth Assessment Report (AR5) of the Intergovernmental Panel on Climate Change (IPCC) will, for the first time, include a separate chapter on climate projections for the near term (i.e., the next few decades). This development reflects the growing importance of adaptation alongside mitigation in the portfolio of policy responses to climate change. Trustworthy projections for the near term are required to inform adaptation policy. It follows that understanding and quantifying the sources of uncertainty in such projections is an important challenge.

[3] Previous research has established that near term projections are not very sensitive to alternative scenarios for greenhouse gas emissions [e.g., Hawkins and Sutton, 2009]. The major reasons are the long lifetime of carbon dioxide in the atmosphere and the long response time of the climate system. However, the situation for emissions of aerosols and their precursors is quite different. Aerosols have a much shorter lifetime in the atmosphere and changes in emissions

\footnotetext{
${ }^{1}$ Department of Meteorology, University of Reading, Reading, UK.

${ }^{2}$ NCAS-Climate, University of Reading, Reading, UK.

Corresponding author: E. J. Highwood, Department of Meteorology, University of Reading, PO Box 243, Reading RG6 6BB, UK. (e.j.highwood@reading.ac.uk)

(C)2012. American Geophysical Union. All Rights Reserved. 0094-8276/12/2012GL052848
}

have the potential to affect climate rapidly. Consequently, uncertainty in future aerosol emissions and atmospheric loading and in the subsequent climate response to such emissions, is a potential source of uncertainty in near term climate projections [Johns et al., 2011].

[4] Aerosols affect the climate through their direct and indirect interaction with the radiation budget. They scatter and absorb shortwave (SW) and longwave (LW) radiation, and interact with clouds, affecting their optical depth and thus their interaction with radiation, as well as affecting precipitation processes [Haywood and Boucher, 2000]. The consensus is that aerosols currently impose a negative forcing on the climate [Forster et al., 2007], although there is significant uncertainty surrounding the magnitude of this forcing.

[5] Results from the international CMIP5 project provide a new opportunity to investigate the sensitivity of climate projections to alternative scenarios for anthropogenic emissions - specifically the RCP scenarios. In these scenarios the emission of primary aerosols, and the pre-cursors of secondary aerosols, were explicitly specified, each model then being free to produce its own self-consistent atmospheric aerosol distributions.

[6] This study is based on analysis of CMIP5 projections with the HadGEM2-ES model [Jones et al., 2011]. Whilst all the RCP scenarios show future reductions in aerosol emissions, differences in the timing and location of implementing pollution controls lead to differences in atmospheric aerosol burden, which have the potential to affect climate. We focus on a comparison between the RCP2.6 and RCP4.5 scenarios, because of relatively large differences in near term aerosol emissions between these two scenarios. Our aims are to understand whether the different emissions lead to significant differences in the projected evolution of climate in the near term, to quantify the extent of any differences, and to gain insights into the mechanisms involved.

\section{Comparison of Near Term Climate in RCP 2.6 and RCP 4.5}

[7] Figure 1 shows global annual mean temperature, sulphate, and GHG forcing time series for the mean of four ensemble members under the RCP 2.6 and RCP 4.5 scenarios simulated by the HadGEM2-ES climate model. It can be seen that between 2018 and 2037 (marked by the black dashed lines), RCP 2.6 has a warmer global mean surface air temperature than RCP 4.5 despite a lower GHG forcing (shown in Figure 1c).

[8] During this time, the global annual mean sulphate load in RCP 2.6 shows a rapid decrease, and is significantly lower than in RCP 4.5. This is due primarily to the reduction in coal use without CCS (Carbon capture and storage), which is a significant source of both $\mathrm{CO}_{2}$ and sulphate 

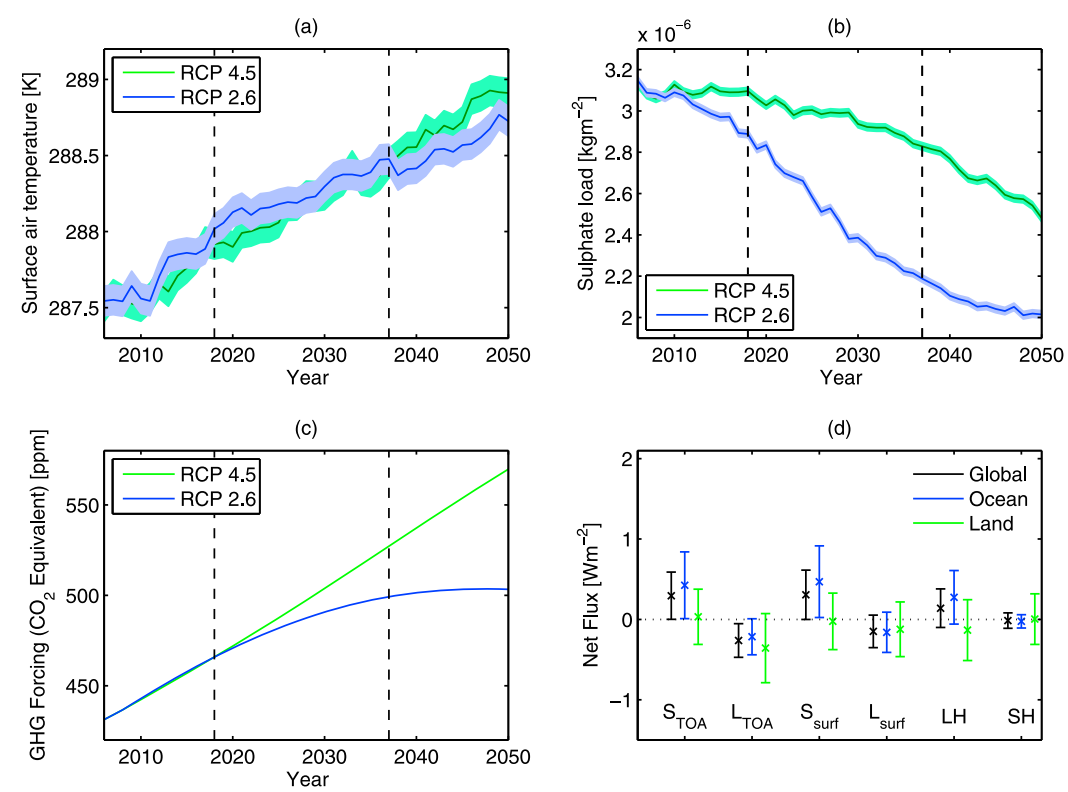

Figure 1. Global and annual mean time series of (a) surface air temperature, (b) sulphate aerosol load, and (c) the GHG forcing expressed in terms of $\mathrm{CO}_{2}$ equivalent in the ensemble mean of four HadGEM2-ES simulations of two scenarios until 2050. RCP 2.6 is in blue and RCP 4.5 is in green. The shading around the lines represents one standard deviation of the global, annual mean of the pre-industrial control run, giving an estimate of the inter-annual variability. (d) The difference in fluxes (net SW and LW TOA and surface radiative fluxes and surface latent heat (LH) and sensible heat (SH) fluxes) between RCP 2.6 and RCP 4.5 averaged over the globe (black), ocean (blue) and land (green) for the period between 2018 and 2037 (marked by black dashed lines on timeseries.)

aerosol emissions [van Vuuren et al., 2011]. The decrease in sulphate emission is therefore a necessary consequence of the methods of $\mathrm{CO}_{2}$ reduction assumed in this scenario in order to achieve such a low radiative forcing target. The rapid decrease in sulphate load under RCP 2.6 reduces its negative forcing (due to both the direct effect and indirect effect on cloud reflectivity), resulting in a positive forcing perturbation which is consistent with a warming of surface temperature.

[9] The difference in global and annual mean components of the energy balance (RCP2.6-RCP4.5) are shown in Figure 1d. There is more net downward shortwave (SW) flux at the top of the atmosphere and at the surface in RCP2.6 consistent with reduced sulphate aerosol (and also with reduced cloud reflectivity or low altitude cloud fraction). The similarity of the surface and top of the atmosphere changes suggests that there is little change in the proportion of SW radiation which is retained/absorbed in the atmosphere (which would be the case if absorbing aerosol were playing a major role). The difference is most apparent over ocean areas. The net downward longwave (LW) flux at the top of the atmosphere is reduced in RCP2.6 due to increased LW emission from the warmer surface. The majority of the additional SW flux reaching the surface is balanced by an increased latent heat flux over ocean regions.

[10] Sulphate is one of four anthropogenically emitted species simulated by HadGEM2-ES: sulphate, fossil-fuel black carbon (FFBC), fossil-fuel organic carbon (FFOC), and biomass-burning aerosol (BB) which is a composite aerosol. The relative importance of the aerosol types is best compared using the optical depth due to each type (i.e., by multiplying the aerosol load by the extinction coefficient for each species, given by Bellouin et al. [2011]. Although the extinction co-efficient is dependent on humidity (except for FFBC), for this comparison we have assumed a humidity of $100 \%$, giving an upper limit on the AODs. Figure $2 \mathrm{a}$ shows that sulphate aerosol is by far the most optically thick anthropogenically emitted aerosol in both scenarios; it therefore remains the focus of this study.

[11] Figure $2 \mathrm{~b}$ shows the spatial distribution of sulphate AOD in RCP 2.6 averaged between 2018 and 2037. Sulphate aerosol is concentrated over south-east Asia, the Indian subcontinent, the Arabian peninsula and Africa. Sulphate AOD over the ocean increases towards the equator. Also shown are the differences in the 2018 to 2037 mean between RCP 2.6 and RCP 4.5 of sulphate AOD, surface air temperature, column integrated liquid cloud droplet number concentration (CDNC) and surface down-welling SW radiation.

[12] RCP 2.6 has a lower AOD (indicated by negative values in Figure 2c) over most regions with the exception of South America and the maritime continent. The largest differences between the scenarios (expressed as a percentage of the mean value in RCP2.6) are found over the continents, but there are significantly lower values in RCP 2.6 over all of the northern hemisphere oceans, as well as over the Indian and tropical Atlantic Oceans. The differences over the northern hemisphere oceans are of particular note as these regions are relatively pristine (low levels of background aerosol - see Figure $2 b$ ), and cloud properties may therefore show greater sensitivity to changes in aerosol.

[13] Differences in cloud droplet number concentration (CDNC) between the two scenarios (Figure 2e) show a similar spatial pattern to AOD, consistent with the expectation that sulphate aerosols are an important source of cloud condensation nuclei $(\mathrm{CCN})$. The difference in $\mathrm{CDNC}$ is mainly negative, implying fewer cloud droplets; if liquid 

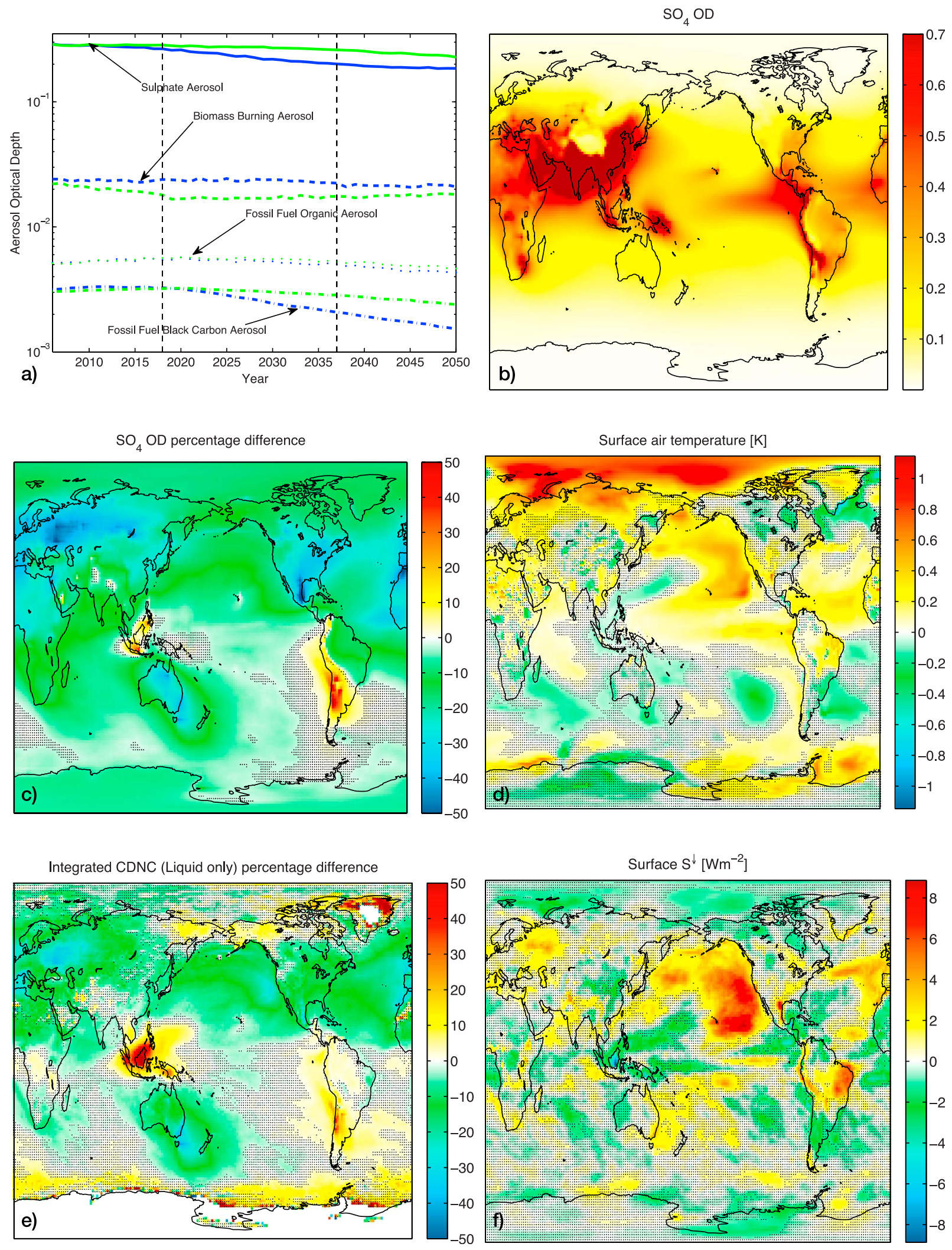

Figure 2. HadGEM2-ES ensemble means of (a) annual global mean timeseries of aerosol optical depth for four anthropogenically emitted species: sulphate aerosol - solid line, biomass burning aerosol - dashed line, fossil-fuel organic aerosol dotted line, and fossil-fuel black carbon aerosol - dot-dashed line. (b) Map of the sulphate optical depth averaged between 2018 and 2037 in RCP 2.6. (c) Map of the difference of 2018 to 2037 average sulphate aerosol load between RCP 2.6 and RCP 4.5. A negative value indicates RCP 2.6 has a lower value than RCP 4.5. The hatching shows where the difference is not significantly different from zero at the $5 \%$ level. $(\mathrm{d}-\mathrm{f})$ Same as Figure $2 \mathrm{c}$, but for surface air temperature, CDNC, and surface downwelling SW radiation respectively. 
water content remains unchanged these droplets will be larger and lead to less optically thick (and reflective) clouds contributing to a reduced aerosol indirect effect in RCP2.6. An exception to the general pattern is the large positive anomaly in CDNC seen over Borneo, but not seen in the sulphate AOD. This is due to large difference in BB aerosol in this region (not shown). RCP 4.5 alone shows an abrupt reduction in $\mathrm{BB}$ aerosol load until 2020 after which emission remains consistently low. This results from a value being placed on carbon emissions from land use changes. Forested areas then become valuable, leading to reforestation and a dramatic decrease in biomass burning [Thomson et al., 2010].

[14] Differences in surface shortwave radiation between the two scenarios (Figure 2f) reflect aerosol direct effects and changes in clouds. The largest anomaly is an increase in downwelling radiation of $5-10 \mathrm{Wm}^{-2}$ over the subtropical northeastern Pacific Ocean in RCP2.6. A smaller increase is also found over the North Atlantic Ocean. Both the Pacific and Atlantic anomalies show a spatial correspondence to regions of decreased $\mathrm{CDNC}$ in $\mathrm{RCP} 2.6$, suggesting that aerosol indirect effects contribute to the increase in surface shortwave radiation. These effects may be more important over the northern oceans than elsewhere because, as previously noted, these are relatively pristine environments.

[15] The difference in surface temperature (Figure 2d) shows an overall warming in RCP2.6, as expected. A local maximum $(0.5-1 \mathrm{~K})$ is located in the northeastern Pacific coincident with the increase in surface shortwave radiation, strongly suggesting that the temperature increase here is a response to the increase in radiation. Other aspects of the pattern of temperature change are likely to reflect redistribution of energy, and feedback processes, in the climate system - for example high latitude amplification is a common signal found in response to many different forcings.

\section{Rapid Warming in RCP 2.6}

[16] The period during which global mean surface temperature in RCP2.6 is higher than in RCP4.5, discussed in the previous section, is directly related to a rapid increase in global mean surface temperature in RCP2.6, between around 2010 and around 2025 (Figure 1a). In this section we investigate the causes of this rapid warming, and relate this event to the comparison with RCP4.5. Figure 3 shows maps of the differences between the 10 year means before and after the rapid warming. In this case a positive value indicates a larger value after the sudden warming identified in Figure 1.

[17] As expected, there is a large reduction in sulphate load, and corresponding decrease in CDNC over most of the northern hemisphere, consistent with a change in the indirect aerosol effect. An increase in the effective radius is also seen (not shown). This reduces the optical depth of the clouds when they are present, meaning more downward shortwave flux is transmitted to the surface. There is also a prominent decrease in cloud fraction over the subtropical northeastern Pacific Ocean which could be a consequence of the impact of reduced sulphate aerosol on cloud lifetime. Lu et al. [2009] show that drizzle rate from clouds in this region is indeed inversely related to aerosol concentration. Kloster et al. [2010] also suggested that a change in cloud water path in their simulations with aggressive aerosol reductions resulted from enhanced drizzle formation. We hypothesise that the localised nature of this feature by comparison with the sulphate and CDNC change is due to the cloud in this region being particularly sensitive to a change in aerosol. Climatologically, this region is a transition zone between open and closed mesoscale cellular convection [Rosenfeld et al., 2011], aerosol concentrations being lower in the open celled regions [Wood et al., 2011]. Although the details of these processes are unlikely to be represented explicitly in global models, the localised strong decrease in cloud fraction in the northeastern Pacific ocean would be consistent with a change in cloud regime driven by decreased aerosol. Other regions show increases in cloud fraction, which cannot readily be explained as a direct response to the decrease in sulphate load. It is likely that instead these reflect non-local adjustments of the coupled ocean-atmosphere system in response to the change in forcing.

[18] Figure 3 also shows the difference in surface shortwave flux (Figure 3d), surface air temperature (Figure 3e), and global energy balance (Figure $3 \mathrm{f}$ ). The predicted increase in surface downward shortwave radiation is seen in the global mean and particularly in the regions of decreased cloud fraction and sulphate load. A negative anomaly in surface SW is co-located with the positive cloud fraction changes. The pattern of surface air temperature change shows large warming over the northern continents and the Arctic, and also a local maximum over the subtropical northeastern Pacific coincident with the region of reduced cloud fraction. The same localised pattern appears in all the simulations of Kloster et al. [2010] that include aerosol reductions, but is absent from their simulations considering only future changes in greenhouse gases.

[19] The surface energy budget shows the expected increases in downward shortwave radiation. In addition there is an increase in downward longwave radiation in response to the increase in GHG concentrations between the two periods, and also reflecting changes in clouds. The warming due to increases in net surface downward radiation is balanced by increases in latent and (over land) sensible heat fluxes.

\section{Discussion and Conclusions}

[20] In this study we have compared projections of near term climate in the HadGEM2-ES model under RCP4.5 and RCP2.6. GHG forcing under these scenarios is almost identical until 2020, and then declines in RCP2.6 relative to RCP4.5. However, between 2018 and 2037 global annual mean surface air temperature is warmer under RCP2.6. The start of this period is characterised by a period of particularly rapid warming.

[21] Our results provide compelling evidence that the warming in RCP2.6 is a result of a rapid decrease in sulphate aerosol load. This decrease is caused by a decrease in sulphur emissions in RCP2.6, as a result of the rapid decrease in coal use needed to reduce GHG emissions. Thus our results highlight the difficulty of reducing the rate of global warming in the near term in this model, even under extreme scenarios for reducing GHG emissions, and is consistent with previous simulations by Wigley [1991] and Johns et al. [2011].

[22] HadGEM2-ES includes a representation of both the direct and first and second indirect effects of aerosol. Our analyses indicate that indirect effects play an important role 
(a) $\mathrm{SO}_{4}$ Load change [\%]

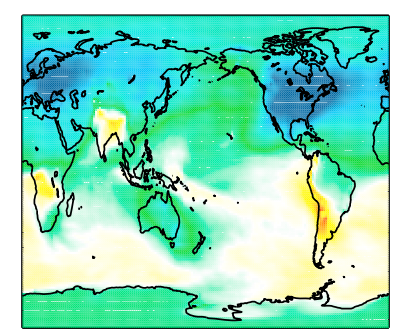

(b) CDNC change [\%]

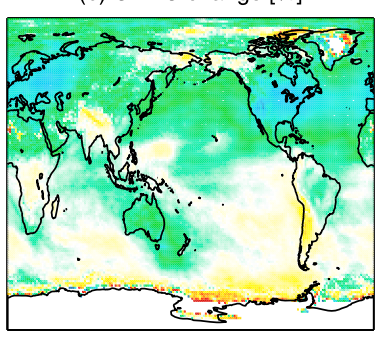

(c) Cloud Fraction [\%]

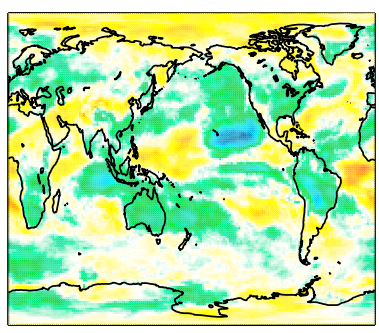

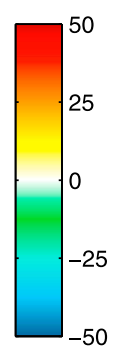
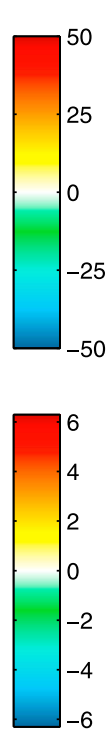

(d) Surface $S^{\downarrow}\left[\mathrm{Wm}^{-2}\right]$

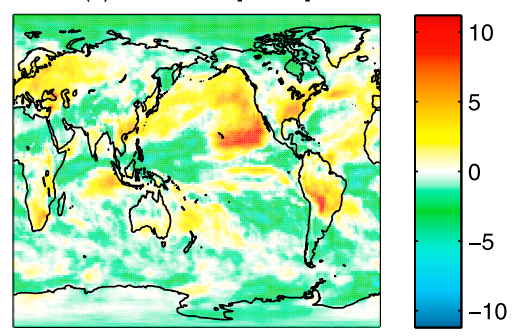

(e) Surface air temp [K]

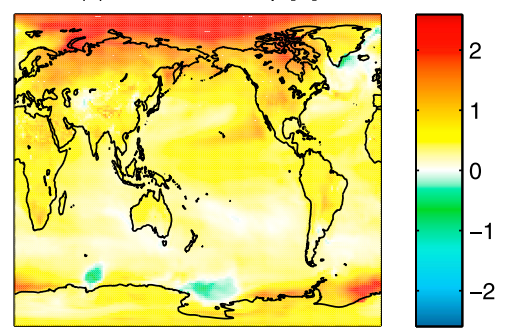

(f) Fluxes

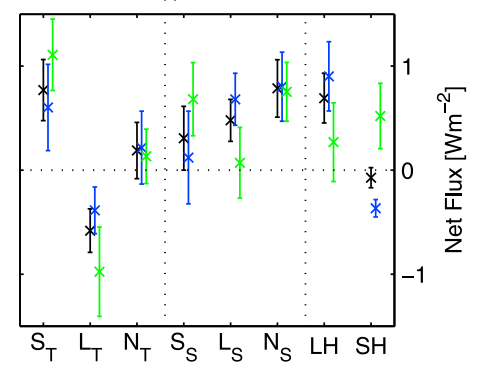

Figure 3. Maps of the difference in the 10 year means (2020 to 2029 mean minus 2006 to 2015 mean) before and after the rapid annual global mean temperature change in HadGEM2-ES simulations under the RCP 2.6 scenario. Variables shown are (a) percentage change in sulphate aerosol load, (b) percentage change in column integrated CDNC (liquid droplets only), (c) change in column cloud fraction, (d) surface $S^{\downarrow}$, (e) surface air temperature, and (f) surface and TOA energy fluxes. A positive change indicates an increase in the later 10 year mean. Figure $3 \mathrm{f}$ shows the change in the net SW (S) and LW (L) and $\operatorname{Net}(\mathrm{N})(\mathrm{SW}+\mathrm{LW}) \mathrm{TOA}$ (subscript T) and surface fluxes (subscript S), and surface latent heat (LH) and sensible heat (SH) fluxes.

in the rapid warming projected under RCP2.6; in particular, changes in sulphate aerosols over the North Pacific and North Atlantic lead to changes cloud properties which contribute to a large anomaly in downwelling surface shortwave radiation over the subtropical northeastern Pacific Ocean. The pattern of surface temperature change is consistent with the expected response to this surface radiation anomaly, whilst also exhibiting features - such as amplification at high northern latitudes - that reflect redistribution of energy, and feedbacks, within the climate system. The substantial but inhomogeneous temperature response demonstrates the importance of aerosol emissions as a key source of uncertainty in near term projections of regional, as well as global, climate.

[23] A natural question is whether the response we have found in HadGEM2-ES is also found in other climate models. In fact there is diversity amongst CMIP5 models (see Figure S1 in the auxiliary material), which is not surprising given the diversity of approaches to representing aerosols effects. ${ }^{1}$ Several models -GFDL-CM3, CSIRO-Mk3-6-0,
CanESM2 and MIROC-ESM-CHEM - appear to give a similar response to HadGEM2-ES whilst many other models show little difference between the scenarios in the near term. Villarini and Vecchi [2012] found little significant difference in tropical mean sea surface temperature between the two scenarios for most CMIP5 models. Ongoing analysis of the response of CMIP5 models to changes in aerosol optical depth suggest that HadGEM2-ES is one of the most sensitive models, however, further detailed analysis of each model is required. As a final caveat, the aerosol reductions proposed in all the scenarios may also be too optimistic, a simulation with aerosol emissions held fixed at 2005 levels would be useful in confirming the role of aerosol changes discussed here.

[24] Acknowledgments. For their roles in producing, coordinating, and making available the CMIP5 model output, we acknowledge the Met Office Hadley Centre, the World Climate Research Programme's (WCRP) Working Group on Coupled Modelling (WGCM), and the Global Organization for Earth System Science Portals (GO-ESSP). This research was supported by the UK Natural Environment Research Council via the National Centre for Atmospheric Science.

[25] The Editor thanks two anonymous reviewers for assisting in the evaluation of this paper.

${ }^{1}$ Auxiliary materials are available in the HTML. doi:10.1029/ 2012 GL052848. 


\section{References}

Bellouin, N., J. Rae, A. Jones, C. Johnson, J. Haywood, and O. Boucher (2011), Aerosol forcing in the Climate Model Intercomparison Project (CMIP5) simulations by HadGEM2-ES and the role of ammonium nitrate, J. Geophys. Res., 116, D20206, doi:10.1029/2011JD016074.

Forster, P., et al. (2007), Changes in atmospheric constituents and in radiative forcing, in Climate Change 2007: The Physical Science Basis. Contribution of Working Group I to the Intergovernmental Panel on Climate Change, edited by S. Solomon et al., pp. 129-234, Cambridge Univ. Press, Cambridge, U. K.

Hawkins, E., and R. Sutton (2009), The potential to narrow uncertainty in regional climate predictions, Bull. Am. Meteorol. Soc., 90, 1095-1107.

Haywood, J., and O. Boucher (2000), Estimates of the direct and indirect radiative forcing due to tropospheric aerosols: A review, Rev. Geophys., $38(4), 513-543$.

Johns, T. C., et al. (2011), Climate change under agressive mitigation: The ENSEMBLES multi-model experiment, Clim. Dyn., 37, 1975-2003.

Jones, C., et al. (2011), The HADGEM2-ES implementation of CMIP5 centennial simulations, Geosci. Model Dev. Discuss., 4, 689-763.

Kloster, S., et al. (2010), A GCM study of future climate response to aerosol pollution reductions, Clim. Dyn., 34, 1177-1194.

Lu, M.-L., A. Sorooshian, H. H. Jonsson, G. Feingold, R. C. Flagan, and J. H. Seinfeld (2009), Marine stratocumulus aerosol-cloud relationships in the MASE-II experiment: Precipitation susceptibility in eastern Pacific marine stratocumulus, J. Geophys. Res., 114, D24203, doi:10.1029/ 2009JD012774.

Rosenfeld, D., R. Wood, L. Donner, and S. Sherwood (2011), Aerosol cloud-mediated radiative forcing: Highly uncertain and opposite effects from shallow and deep clouds, paper presented at WCRP Open Science Conference, World Clim. Res. Programme, Denver, Colo., 24-28 Oct.

Thomson, A., et al. (2010), RCP4.5: A pathway for stabilization of radiative forcing by 2100, Clim. Change, 109, 77-94.

van Vuuren, D., et al. (2011a), RCP2.6: Exploring the possibility to keep global mean temperature increase below $2^{\circ} \mathrm{C}$, Clim. Change, 109, 95-116.

Villarini, G., and G. A. Vecchi (2012), Twenty-first-century projections of North Atlantic tropical storms from CMIP5 models, Nat. Clim. Change, 2, 604-607.

Wigley, T. M. L. (1991), Could reducing fossil-fuel emissions cause global warming?, Nature, 349, 503-506.

Wood, R., C. Bretherton, D. Leon, A. Clarke, P. Zuidema, G. Allen, and H. Coe (2011), An aircraft case study of the spatial transition from closed to open mesoscale cellular convection over the southeast Pacific, Atmos. Chem. Phys., 11, 2341-2370. 